\title{
Mouse Models in Bone Fracture Healing Research
}

\author{
Melanie Haffner-Luntzer ${ }^{1}$ - Anna Kovtun ${ }^{1}$ • Anna E. Rapp ${ }^{1}$ - Anita Ignatius ${ }^{1}$
}

Published online: 4 April 2016

(C) Springer International Publishing AG 2016

\begin{abstract}
Bone fracture healing is a tightly regulated process involving many cell types, mediators, and signaling pathways and is still not well understood. During decades, bone healing was mainly studied in large animals, including dogs, rabbits, or sheep. In recent years, mice have become increasingly popular as a model organism for fracture healing research. The benefits of mice are the possibility of genetic modification, the availability of clinically relevant disease models, low costs, easy handling, short breeding cycles and fast regeneration. Furthermore, various fracture healing models have been developed, which are adapted to the small skeleton and allow standardized investigations. However, attention has to be paid to species differences between mice and humans and the influence of the background strain, age and gender of the mice. This review focuses on the main advantages and disadvantaged of mice as a model organism for bone fracture healing research and critically discusses the translational aspect.
\end{abstract}

This article is part of the Topical Collection on Preclinical Animal Models in Regenerative Medicine

Anita Ignatius

anita.ignatius@uni-ulm.de

Melanie Haffner-Luntzer

melanie.haffner-luntzer@uni-ulm.de

Anna Kovtun

anna.kovtun@uni-ulm.de

Anna E. Rapp

anna.rapp@uni-ulm.de

1 Institute of Orthopedic Research and Biomechanics, University Medical Center Ulm, Helmholtzstraße 14, 89081 Ulm, Germany
Keywords Fracture healing - Mouse models · Bone · Transgenic mice $\cdot$ Translational research

\section{Introduction}

Fractures are the most common disorders of the musculoskeletal system $[1 \bullet \bullet, 2]$. Although orthopedic treatment has improved considerably in recent decades, $5-10 \%$ of all fractures still display delayed or non-healing [3, 4]. Insufficient bone repair leads to increasing numbers of revision surgeries, greatly decreased quality of life in affected patients and an enormous socioeconomic burden due to longer hospitalization and rehabilitation periods [5*0]. Reasons for delayed bone regeneration are manifold, including inappropriate mechanical stabilization, comorbid diseases, age, pathological hormone and nutrition status, additional pharmacological therapy and genetic variations [3]. However, the interplay of all these factors and the underlying cellular and molecular mechanisms are still not well understood. Therefore, there remains the need to unravel the complex biological processes involved during fracture healing to develop new strategies for ensuring uneventful bone repair. Due to the complexity of fracture healing, in vitro and in silico models are helpful but not sufficient, and therefore, in vivo animal models are required. During earlier decades, fracture healing was mainly studied in large animals, including dogs, rabbits and sheep [6-10]. The benefits of these species are the large skeletal size and a similar bone structure to humans with the presence of a Haversian remodeling system. However, excessive husbandry costs, difficult handling of large animals and the lack of established transgenic animals and evaluation methods promoted rats as a new model organism for fracture repair research in the 1990s. The major advantages of rats are low costs, easy handling, short breeding cycles and faster regeneration. However, 
genetic modification of rats is rather limited. Therefore, in recent years, mice have become increasingly popular.

This review will focus on the advantages and disadvantages of mice as a model organism for bone healing research, as well as on established murine bone healing models. Additionally, the translational aspect of mouse models in fracture healing research will be analyzed critically.

\section{The Mouse Models in Biomedical Research}

Over recent decades, the mouse became the most frequently used animal model in biomedical research due to easy handling and low husbandry costs compared to larger animals [11]. Furthermore, the reproductive cycle is short and mice produce a large number of progeny. In addition, the sequencing of the mouse genome in 2002 revealed a very high number of orthologs and homologs to human genes, making the mouse a valuable model organism for many human genetic conditions. Most strains used in biomedical research are inbred strains, which are highly genetically standardized due to sibling mating for a minimum of 20 generations. Further advantages of mice are the availability of specific analytic tools, including monoclonal antibodies against a broad variety of antigens to target individual molecules in vivo and the availability of sophisticated in vivo imaging systems.

At present, a large number of mouse strains with different genetic alterations are available, including "mutant mice" that are the product of spontaneous single-gene mutations. Additionally, in previous decades, many targeted genetically modified mouse strains were developed. In principle, there are two approaches to generate genetically modified mice. The first method was introduced in the 1980s by Gordon and colleagues and involves the microinjection of DNA constructs into the pronuclei of fertilized mouse oocytes [12]. By this method, transgenic mice with random genomic insertion of the injected DNA are produced. Therefore, the expression of the transgenes is highly influenced by endogenous enhancers and silencers. This method is commonly applied to insert new genetic information into the mouse genome or to produce overexpression of endogenous genes. The second more targeted method is based on the manipulation of embryonic stem (ES) cells with DNA constructs homologous to the gene of interest. ES cells, in which the inserted DNA construct is recombined with the genomic DNA, are selected and transferred into mouse blastocysts. Regarding the type of modification one wishes to generate, the DNA construct can carry null alleles to generate constitutive knockout mice or modified alleles of the gene of interest to produce knockin mice. Furthermore, it is possible to replace the endogenous mouse gene, for example, with the human homolog. In addition to constitutive knockouts and knockins, the generation of inducible models is feasible. The oldest system for inducible gene targeting is the Cre-lox system. This system is based on the transgenic expression of the Cre recombinase of bacteriophage $\mathrm{P} 1$ and the presence of its recognition sites, the loxP (locus of cross-over of P1) sites [13]. The loxP sites consist of two 13-bp inverted repeats, flanking an 8-bp non-palindromic region that gives the loxP site directionality [13]. Alleles that are flanked by a loxP site are termed "floxed." The mating of mice with floxed alleles to mice transgenic for Cre recombinase results in the generation of knockouts. Additionally, gene expression can be activated when the floxed sequence is a transcription inhibitor. The Cre-lox system also allows the production of cell- or lineage-specific gene deletion/activation by breeding floxed mice to mice in which a specific promoter controls the expression of the Cre recombinase. Furthermore, there are Cre recombinases, whose cleaving activity is inducible by application of estrogen analogs, including tamoxifen. This is a valuable tool to produce a postnatal knockout that would be lethal during embryogenesis. In addition to the Cre-lox system that results in a permanent genetic alteration, there are systems allowing genetic switching, including the tetracycline-based Tet-on/off system [14]. It is also possible to create mice with targeted depletion of specific cell populations. Here, cell ablation is based on the cell-specific expression of toxins, including the diphtheria toxin, inhibition of DNA elongation or induction of apoptosis [15].

When choosing a strain for bone research, the genetic background must be considered, because this influences the bone phenotype and the manifestation of genetic manipulation. Akhter and colleagues compared the material properties of bone of several inbred mouse strains and found differences in bone mineral density (BMD), elasticity, hardness and biomechanical properties $[16,17]$. Bone regeneration processes also depend on the genetic background. The analysis of the bone regeneration capacity of 12 inbred strains displayed considerable differences among the strains [18]. Furthermore, Manigrasso and O'Connor demonstrated a more rapid bone healing in C57BL/6 compared to DBA/2 and $\mathrm{C} 3 \mathrm{H}$ mice [19]. Unpublished results from our group corroborate these findings, because we detected considerable differences in fracture healing between the C57BL/6J, C57BL/6N, Balb/cByJ, and $129 \mathrm{~Sv} /$ Tac strains (Fig. 1). In addition to strain and genetic manipulations, age and gender also strongly influence bone biology (Fig. 1) and should be considered when planning an experiment.

\section{Murine Bone Healing Models}

Although the bone structure of mice and humans differs considerably, the process of fracture healing is very similar, making the mouse a good model for fracture-healing research [21, 22]. In both species, initial tissue damage and rupture of blood vessels lead to activation of inflammatory cells. This first 

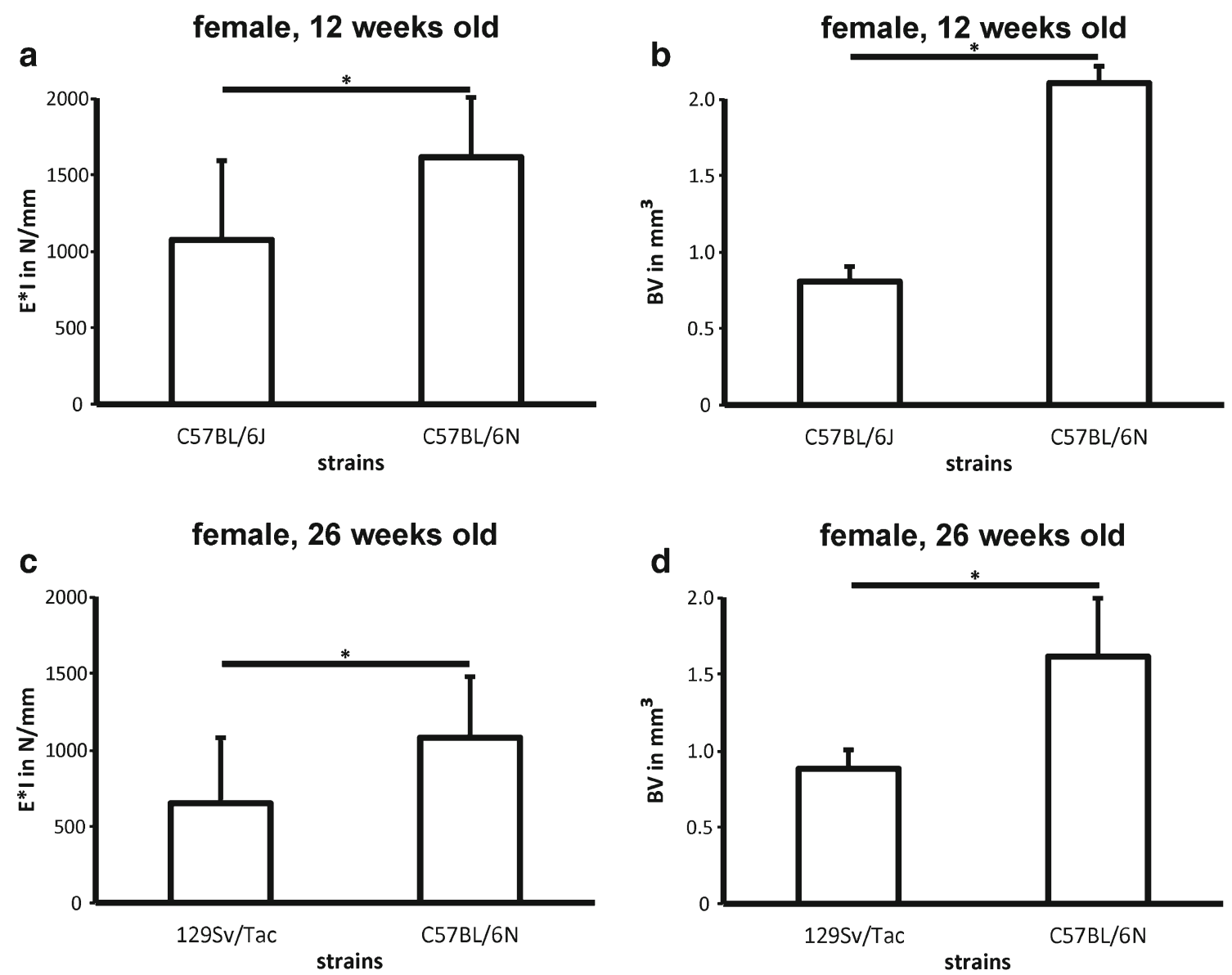

male, 12 weeks old

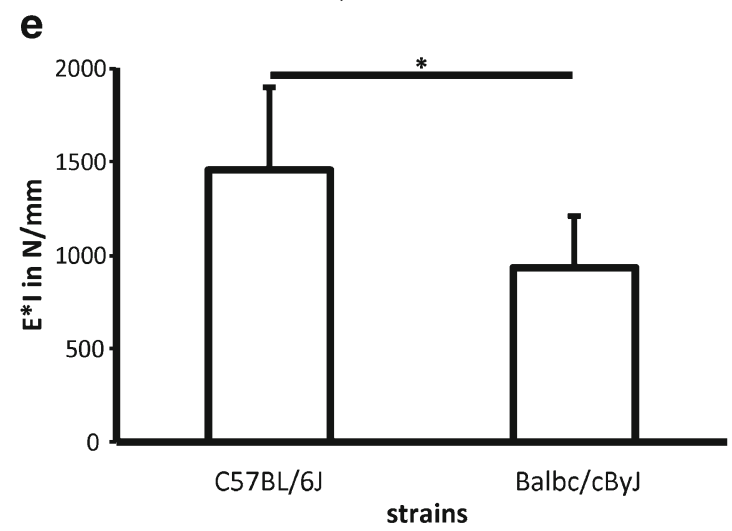

Fig. 1 Progress of fracture healing after 21 days varied in different mouse strains, ages and gender. Mice of different genetic backgrounds, different ages at the day of the surgery and different gender were subjected to a standardized femur osteotomy stabilized by a semi-rigid external fixator as described previously [20]. All mice were sacrificed at day 21 after surgery and the bending stiffness of the fractured femur was

inflammatory phase of fracture healing is crucial for initiation of the repair phase, which aims to restore the physiological biomechanical competence of the fractured bone. In both mice and humans, the course of fracture healing with intramembranous or endochondral ossification is highly

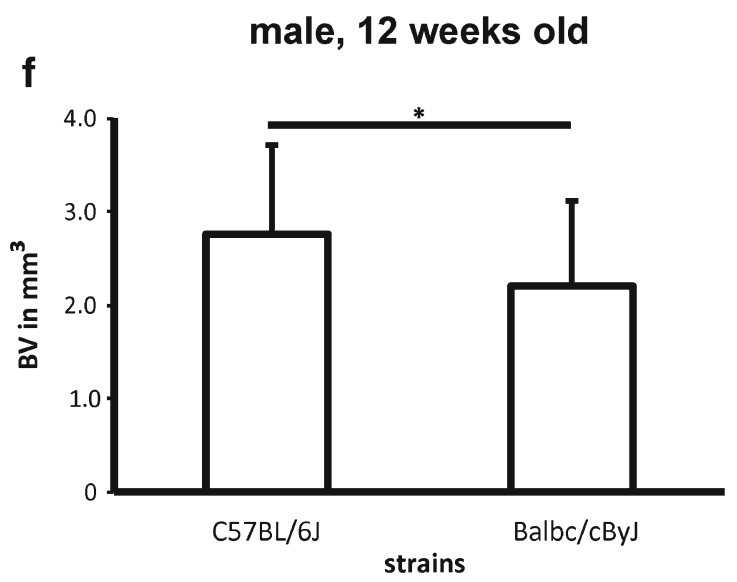

evaluated by 3-point bending test (Fig. 1a, c, e), and the bone volume of the fracture callus was evaluated by $\mu \mathrm{CT}$ analysis (Fig. $1 \mathbf{b}, \mathbf{d}, \mathbf{f}$ ). a, b Comparison of 12-week-old female mice of the C57BL/6J and C57BL/ $6 \mathrm{~N}$ strains. c, d Comparison of 26-week-old female mice of the 129Sv/ Tac and C57BL/6N strains. e, f Comparison of 12-week-old male mice of the C57BL/6J and Balbc/cByJ strains. $n=5-12,{ }^{*} p<0.05$, Student's $t$ test

influenced by the type of fracture, concomitant soft tissue trauma and the biomechanical stabilization of the fracture. Therefore, several rodent bone-healing models with different experimental setups were developed in recent years to mimic the clinical situation. 
In 1984, Bonnares and Einhorn developed a technique to create standardized, closed fractures in rats, which was later adapted to the mouse. This model is based on the insertion of an intramedullary pin and subsequent fracturing of the bone by means of a blunt guillotine driven by a dropped weight [23]. This so-called Einhorn model models impact fractures, thus having high clinical relevance. However, fracture localization and geometry are difficult to standardize. Moreover, in many publications, comminuted fractures were depicted when the guillotine was used for fracturing. Open experimental approaches allow the production of standardized osteotomies (e.g., by using Gigli wire or oscillating saws). This more standardized "fracture" geometry and location is advantageous, decreasing deviations and, thus, providing better evidence on molecular mechanisms behind bone regeneration. Osteotomies can also be applied to the metaphyseal region of the femur [24] or for the generation of critically sized defects in the diaphysis [25]. The model chosen for the bone injury implicitly influences the healing process. Klein and colleagues compared the healing outcome of equally fixed closed fractures and open osteotomies and found delayed healing of the osteotomies [26]. This may be due to the different grades of soft tissue injury.

In addition to the different methods to produce fractures, fracture fixation is of particular importance. Similar to clinics, stabilization techniques in mice include intramedullary nailing, external fixators, and plate osteosyntheses. The simplest way to stabilize fractures is the insertion of an intramedullary pin through the intracondylar notch. In most cases, an injection needle or a wire is used. These simple implants do not provide rotational or axial stability; thus, callus size may vary considerably within an experiment. During recent years, biomechanically standardized implants for fracture stabilization methods have been developed. Improved intramedullary implants are compression screws and locking nails. The first provides axial and rotational stability by means of interfragmentary compression and can be used for reduction and fixation of closed fractures [27]. The locking nail is a more elegant fixation device. Its use is combined with the creation of an osteotomy rather than a fracture. The locking nail provides rotational and axial stiffness due to bi-cortical locking pins proximal and distal of an osteotomy. Therefore, different gap sizes can be adjusted [28]. The major disadvantage of intramedullary implants is the disruption of the integrity of the endosteum and the bone marrow that both contribute to the healing process; thus, the healing zone itself might be influenced by the implant. Furthermore, implant removal, for example, for mechanical testing of the healed bone and for histologic processing, may lead to the disruption of the regenerated tissue. To overcome the drawbacks of intramedullary implants, external fixators were developed [29]. As for the locking nail, different osteotomy sizes can be created to study bone regeneration or even to produce fracture non-unions.
The fixation stiffness can be adjusted by altering the fixatorbody stiffness or the length of the mounting pins. The selected stiffness of the external fixator dictates the healing process. Rigid fixation in combination with small osteotomy gaps leads to primary fracture healing via intramembranous bone healing, while more flexible fixator configurations foster secondary fracture healing via the formation of a cartilaginous callus and endochondral ossification [29]. The major advantage of the external fixator is that it is fixed to the bone at some distance from the osteotomy and thus does not directly interfere with the healing process. Furthermore, the external fixator is easily removed post mortem. Although one might think that the external fixator bears the risk for pin-associated infections, in numerous mice of different genotypes, we never observed implant-related infections. Analogous to fixation techniques in humans, plate osteosyntheses for the murine femur were also designed [30]. As for external fixators, the stiffness of plate osteosyntheses can be adjusted, so both primary and secondary bone healing can be achieved. Like the external fixator, the plate osteosynthesis is often combined with an osteotomy. However, due to its internal location very close to the periosteum, there is the risk of hampered callus formation.

\section{Murine Disease Models Used in Fracture Healing Research}

It is known from clinical practice that not only biomechanical stabilization but also patient-specific factors and comorbid conditions can strongly influence bone metabolism and fracture healing. Evidence suggests that sex, age, hormone status, comorbidities, including diabetes mellitus and rheumatoid arthritis, several drugs, including non-steroidal anti-inflammatory drugs and glucocorticoids, concomitant traumata, smoking, and alcohol abuse can interfere with fracture healing [31]. However, less is known about the molecular reasons for disturbed fracture healing in comorbid patients. Here, another important advantage of mice used in bone and fracture research is the availability of many clinically relevant disease models to investigate molecular mechanisms of delayed healing. Additionally, due to the rapid metabolism of mice, the effect of substances and treatments on bone can be studied within a more reasonable time than in larger animals. The best-established clinically relevant murine disease model is the induction of postmenopausal osteoporosis by ovariectomy (OVX) in female mice. Following OVX, the animals first display a very rapid loss of trabecular bone, resulting in an osteopenic phenotype. The mechanism behind that is a shift in bone remodeling toward bone resorption due to the lack of ovary-derived estrogen, mimicking the human situation of high bone turnover in the early postmenopause [32]. A limitation of this animal model is that the total BMD loss is less 
than in human patients [33]. However, during bone healing, ovariectomized mice display delayed fracture bridging [34, 35•] similar to osteoporotic patients [36]. The model of OVX-induced postmenopausal osteoporosis and delayed fracture healing in mice is well-established and described in many research papers applying this experimental setup (see examples in Table 1). There is good evidence of decreased bone formation in the fracture callus of OVX mice during the intermediate and late phases of healing. However, there remains a lack of data analyzing the influence of OVX on the early phase of fracture healing.

The mouse is also a valuable model for age-related research focusing on bone. In recent years, age-related osteoporosis has increasingly become a focus of translational research. Aging mice, like aging humans, show a progressive decrease in total bone mass [50-52]. However, experiments using 12-monthold or even older mice are very time-consuming. Therefore, other mouse models mimicking aging were used, including the SAMP6- and the Klotho-deficient mice, which display accelerated aging associated with a senile low-turnover osteopenia [53-55]. During fracture healing, both aged mice and SAMP6-deficient mice were demonstrated to have a reduced healing capacity resulting in delayed bone regeneration and callus maturation [38, 39•]. However, there remains a lack of evaluation of the molecular causes for delayed fracture healing in aged mice.

Another disease with great relevance for bone and fracture healing is diabetes. Type I diabetic patients frequently display a lower bone mass, a destroyed bone microarchitecture, and, therefore, a higher fracture risk [56]. Additional to the higher number of fractures in diabetic patients, the risk for delayed healing or non-union formation is substantially higher in both type I and type II patients [57]. Many different murine models for either type I or type II diabetes were developed, mimicking specific bone-related aspects of the human disease, as summarized in two review articles from Fajardo et al. [58 ] and Forslund et al. [59]. Most of the diabetic mice displayed delayed callus maturation and fracture healing.

Despite the inter-species differences between mice and humans in inflammatory mechanisms, the bone turnover is regulated by the immune system in a similar manner. Therefore, different chronic inflammatory comorbid conditions, including rheumatoid arthritis and diabetes, were shown to induce an osteopenic phenotype in both species [60-65]. The acute inflammation associated with concomitant trauma also influences fracture healing both in humans and in rodents $[5 \bullet \bullet, 48 \bullet, 66,67]$. For example, in both polytrauma patients and polytraumatized mice, the excessive activation of the systemic inflammatory response leads to delayed healing and increased risk for non-unions [5••, 48•, 68, 69]. However, the animal model of severe trauma should be carefully evaluated for the prediction of fracture-healing outcome because different concomitant injuries can shift bone regeneration processes in different directions. Therefore, traumatic brain injury patients often suffer from ectopic bone formation and prominent osteogenic differentiation [70], whereas patients with additional thoracic trauma develop systemic inflammatory response syndrome [71], which increases the risk of delayed fracture healing. Additionally, approximately $10 \%$ of trauma patients develop hemorrhagic shock [72], although its influence on fracture healing in humans is not completely understood. Nevertheless, it is speculated that hemorrhage impairs fracture healing due to decreased soft-tissue perfusion [47]. The mentioned traumata have also been established in mouse models (see Table 1) and clearly demonstrated that the mouse is able to mimic pathological processes in trauma patients to a very close extend and, therefore, is a valuable tool to gain a deeper understanding of the healing course under inflammatory conditions.

In addition to the aforementioned murine disease models, models for alcohol abuse, cigarette smoking, and drug intake were used for fracture-healing studies [43•, 44, 73, 74].

\section{Suitability and Translational Impact of Mouse Models in the Area of Bone Metabolism and Fracture Healing}

The development of many existent bone-targeting therapeutic agents was based on murine experiments, indicating that the fundamental mechanisms of bone biology are similar between human and mouse, although their bone structures differ. One of the first identified signaling pathways was the receptor activator of NF-KB ligand (RANKL)/osteoprotegerin (OPG) system. OPG is a secreted protein that was shown to inhibit osteoclastogenesis in mice [75]. Transgenic mice overexpressing OPG displayed an osteopetrotic phenotype, thus confirming the osteoanabolic function of this protein [75]. Lacey et al. [76] identified a polypeptide ligand for OPG, which activates mature osteoclasts and increases osteoclast formation. In the same year, Yasuda et al. [77] discovered that this OPG ligand was identical to the RANKL protein. In 2000, the same group demonstrated that both OPG and RANKL are produced by osteoblastic cells, whereas the receptor for RANKL is expressed on preosteoclastic cells and mature osteoclasts [78]. Therefore, the interaction of these proteins is important for the regulation of osteoclast formation by osteoblasts. In recent years, a therapeutic antibody against RANKL, densoumab, was developed. After treatment of human RANKL knockin mice with denosumab, these mice displayed decreased osteoclast surface, increased bone mass [79], and significantly accelerated bone formation in the fracture callus [80]. Clinical studies of denosumab demonstrated a significantly increased BMD in postmenopausal women [81-84]. Additionally, denosumab was shown to decrease the fracture risk $[85,86]$. The next step would be to test whether the 


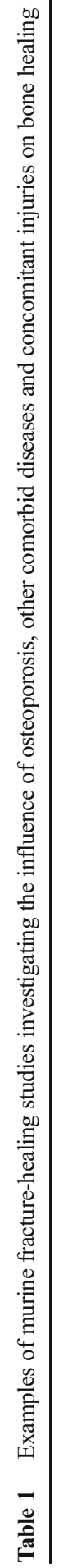

D $\quad \dot{\bar{n}} \bar{m}$

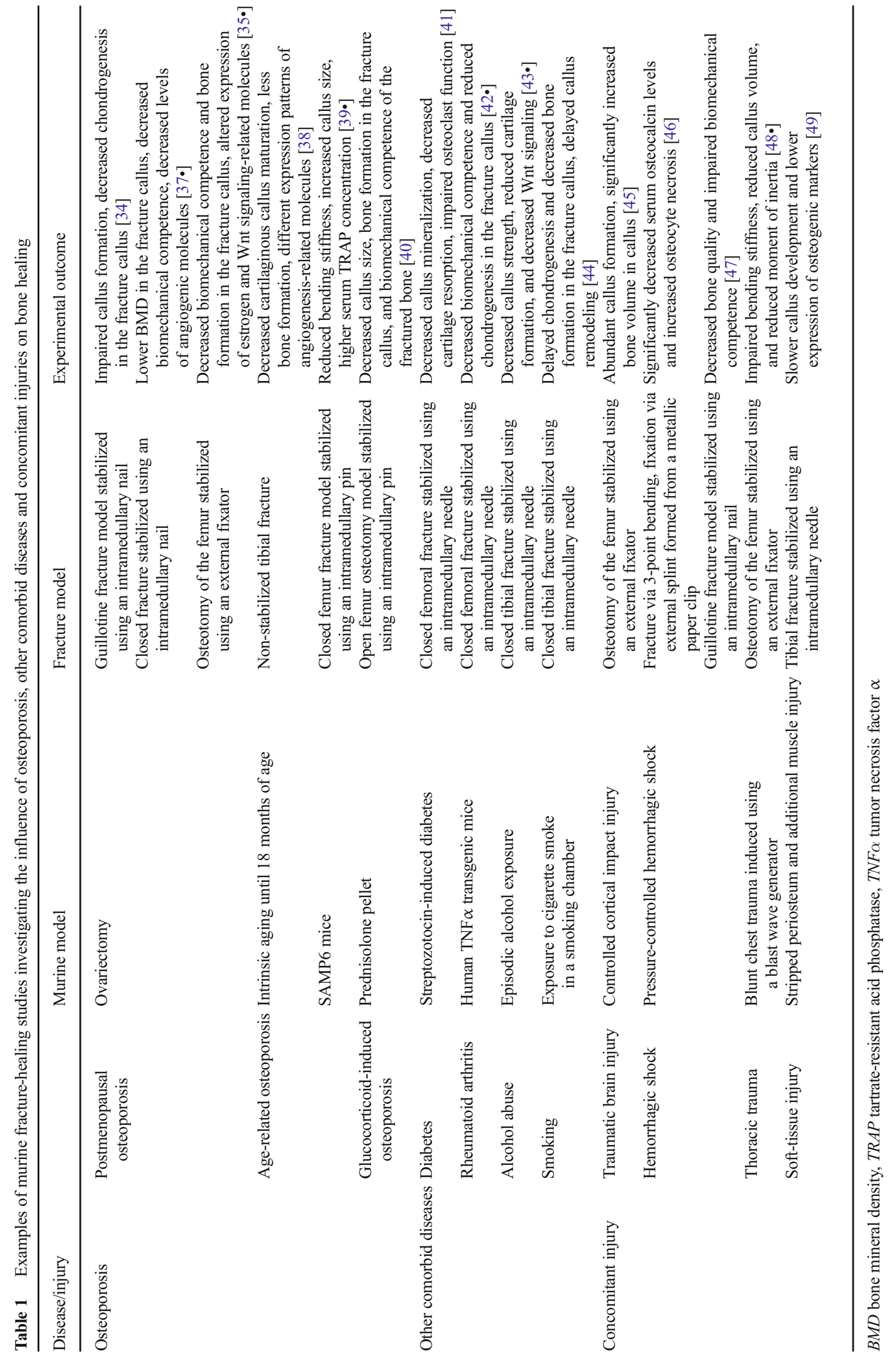


antibody can also accelerate bone regeneration in humans. In summary, the discovery of the RANK/RANKL/OPG interplay in mice and the development of the anti-RANKL antibody for use in humans is a good example to demonstrate the translational impact of bone research using transgenic mouse models. Another therapeutic antibody developed in mice is romosozumab, a monoclonal antibody against sclerostin. Although the first indications that the sclerostin gene may be involved in bone homeostasis came from a naturally occurring mutation in humans suffering from van Buchem disease [87], the understanding of the molecular mechanisms of sclerostin action were gained in mice. Sclerostin-overexpressing mice exhibit low bone mass and decreased bone strength due to a significantly reduced osteoblast activity [88]. Further studies demonstrated that sclerostin is a negative regulator of osteoanabolic Wnt/beta-catenin signaling [89]. Preclinical studies demonstrated that antagonizing sclerostin using a monoclonal antibody increased bone formation, bone strength, and fracture healing in rodents [64, 90-92]. Currently, romosozumab is under investigation in a clinical phase II trial, showing promising initial results in postmenopausal women with low BMD [93•]. Inhibition of cathepsin K (CatK) is another promising approach to osteoporosis treatment. CatK is a cysteine protease responsible for the degradation of type I collagen and is abundantly expressed in osteoclasts [94]. In actively resorbing osteoclasts, CatK accumulates in lysosomes close to the ruffled membrane and is secreted into the extracellular space [95]. CatK deficiency in different knockout mice led to high bone mass [96, 97], whereas overexpression of CatK resulted in accelerated bone turnover and reduced trabecular bone volume [98]. These findings led to the development of several CatK inhibitors for clinical applications, including odanacatib. Odanacatib is a nitrile-based molecule displaying high potency for CatK inhibition and lower affinity for other cathepsins [95]. A long-term phase II trial on odanacatib showed increased BMD and reduction of bone resorption markers in osteoporotic women [95]. The phase III Long-Term Odanacatib Fracture Trial (LOFT) demonstrated an approximately $50 \%$ decreased risk of both primary and secondary osteoporotic fractures in postmenopausal women [99].

The bone morphogenetic protein (BMP) signaling cascade is one of the most important molecular pathways during bone development and healing. BMPs are secreted proteins of the transforming growth factor beta superfamily, which are crucially involved in embryonic development of many organs. Consequently, the majority of BMP knockout mice are lethal at an early embryonic stage [100, 101]. However, the conditional mesenchymal BMP knockout mouse revealed the crucial role of BMP2 in fracture healing [102]. Both in mice and larger animals, recombinant BMP2 (rhBMP2) was successfully tested as an osteoinductive therapy to enhance fracture healing [103, 104]. Meanwhile, rhBMP2 is now established in clinical practice to treat patients with orthopedic complications, including delayed healing and non-union formation [105, 106].

Research in mice also led to the development of antiinflammatory drugs, which reduce inflammation and bone destruction in joints of rheumatoid arthritis patients [107]. One example is tozilizumab, a humanized mouse anti-interleukin-6 receptor antibody, that blocks IL-6-mediated inflammatory signaling, thus reducing the number of neutrophils in synovia and joint swelling and attenuating structural joint damage [108].

Despite many promising results gained in the mouse, the transfer of such findings to the clinic is often difficult and requires careful additional evaluation. In particular, in mouse models of inflammatory conditions, the inter-species differences in the cross talk between bone and the immune system should be taken into account, because the murine immune system is quite different from the human in many aspects. In humans, 50-70\% of leukocytes are polymorphonuclear neutrophils, whereas mouse blood is lymphocyte-rich with only $10-25 \%$ of neutrophils [109]. Even more prominent differences can be detected on the molecular level. For example, mouse-immune cells do not express ICAM3, caspase 10, or several classes of Fc receptors, including Fc $\alpha$ RI and Fc $\gamma$ RIIA and $C$ [109]. Therefore, the mouse can only model human bone-affecting inflammatory conditions to a limited extent. For example, despite many available models for rheumatoid arthritis, it is not possible to mimic in mouse the whole course of the human disease, including all molecular and pathological events. Therefore, Seok et al. recently questioned the applicability of mouse trauma models, indicating that in recent years, approximately 150 clinical trials intended to block inflammatory response in critically ill patients failed [110•]. The authors explored the correlation of expression profiles of genes involved in inflammatory responses in both mice and humans. The authors compared trauma patients with different murine trauma models and found very poor correlation in inflammatory processes between the two species. However, the study was strongly criticized due to several limitations, including failed age and analysis timepoints matching, different concentrations of applied LPS, and the comparison of large patients cohort with a single inbred strain [111••, 112]. Moreover, these data were contradicted by a de novo analysis of the same datasets performed by Takao et al. [113], with special focus not on the whole genome but on genes whose expression levels were significantly changed. This analysis showed good correlation of inflammatory processes both between different trauma models and between human and murine trauma. These results indicate that the understanding of limitations of the applied models is crucially important for the appropriate evaluation of data [111••, 113].

One possibility to overcome the problem of biological differences between mice and humans at least in part is the use of xenograft and humanized mouse models. Xenograft models are based on immune-deficient mice, which allow the 
transplantation of human cells and tissues into the murine organism without rejection [114]. This approach is commonly used to perform basic studies on human tissues, cancer development and stem cell function in a complex, living organism, but outside the human body $[115,116]$. Xenograft mouse models can similarly be used to study human bone biology: Recent studies demonstrated the successful generation of a bioengineered human organ bone in immune-deficient mice $[117,118]$. In these studies, degradable synthetic scaffolds were seeded using human osteogenic progenitor cells prior to subcutaneous implantation to generate vascularized and viable human bone. The authors used this novel xenograft model to investigate the metastasis of human cancer cells to the human organ bone $[117,118]$.

Beyond the transplantation of human tissues, immunedeficient mice can be used for engraftment of a human immune system by the injection of human hematopoietic stem cells. These chimeric mice are termed "humanized mice" [115] and are generally useful to study human immune cell biology in the murine organism. Such humanized mice are used to investigate human anti-tumor immune response, infectious diseases, graftversus-host disease, autoimmunity and many other research questions $[114,119]$. A completely new approach is the combination of the humanized mouse model with tissue-engineered bone constructs. In this setup, the interaction of human hematopoietic stem cells and their physiological niches in the bone marrow has recently been investigated [119].

Although xenograft and humanized mouse models have intrinsic limitations due to their great complexity, they could potentially be used to investigate human bone disorders, regeneration and trauma response.

\section{Conclusion}

In conclusion, inter-species differences should be taken into account in translational studies, because there are important biological differences between the mouse and human, particularly when considering the inflammatory response or the bone remodeling system. However, many osteoanabolic drugs have already been developed using mice and have shown considerable therapeutic success in human osteoporotic patients. Because the fracture healing process is similar in mice and humans and many highly standardized murine fracture models are available, we conclude that research using mouse models will have a significant translational impact on clinical fracture treatment in the future.

Acknowledgments The authors are partly granted by the German Research Foundation (Collaborative Research Center CRC1149).

\section{Compliance with Ethical Standards}

Conflict of Interest Melanie Haffner-Luntzer, Anna Kovtun, Anna E. Rapp, and Anita Ignatius declare that they have no conflict of interest.

Human and Animal Rights and Informed Consent This article does not contain any studies with human or animal subjects performed by any of the authors.

\section{References}

Papers of particular interest, published recently, have been highlighted as:

- Of importance

•• Of major importance

1.• Claes L, Recknagel S, Ignatius A. Fracture healing under healthy and inflammatory conditions. Nat Rev Rheumatol. 2012;8:13343. Review about the process of fracture healing and the influence of inflammation.

2. Einhorn TA. The cell and molecular biology of fracture healing. Clin Orthop Relat Res. 1998:S7-21.

3. Einhorn TA. Enhancement of fracture-healing. J Bone Joint Surg Am. 1995;77:940-56.

4. Tzioupis C, Giannoudis PV. Prevalence of long-bone non-unions. Injury. 2007;38 Suppl 2:S3-9.

5.• Hak DJ, Fitzpatrick D, Bishop JA, Marsh JL, Tilp S, Schnettler R, et al. Delayed union and nonunions: epidemiology, clinical issues, and financial aspects. Injury. 2014;45(2):S3-7. Clinical update about delayed fracture healing.

6. Clark Jr HB, Hayes PA. A study of the comparative effects of "rigid" and "semirigid" fixation on the healing of fractures of the mandible in dogs. J Bone Joint Surg Am. 1963;45-A:731-41.

7. Olerud S, Danckwardt-Lilliestrom G. Fracture healing in compression osteosynthesis in the dog. J Bone Joint Surg (Br). 1968;50:844-51.

8. Veneroni G, Boccadoro B, Pluchino F. Fixation of P-32 in the focus of a fracture and in osseous callus in the long bones in rabbits. Arch Ortop. 1962;75:1338-41.

9. Nunamaker DM, Perren SM. A radiological and histological analysis of fracture healing using prebending of compression plates. Clin Orthop Relat Res. 1979:167-74.

10. Claes LE, Wilke HJ, Augat P, Rubenacker S, Margevicius KJ. Effect of dynamization on gap healing of diaphyseal fractures under external fixation. Clin Biomech (Bristol, Avon). 1995;10: 227-34.

11. The Laboratory Mouse. Burlington, MA: Academic Press; 2004.

12. Gordon JW, Scangos GA, Plotkin DJ, Barbosa JA, Ruddle FH. Genetic transformation of mouse embryos by microinjection of purified DNA. Proc Natl Acad Sci U S A. 1980;77:7380-4.

13. Sauer B. Inducible gene targeting in mice using the Cre/lox system. Methods. 1998;14:381-92.

14. Sprengel R, Hasan MT. Tetracycline-controlled genetic switches. In: Feil R, Metzger D, editors. Handb Exp Pharmacol. 2007;4972.

15. Miller RL. Transgenic mice: beyond the knockout. Am J Physiol Renal Physiol. 2011;300:F291-300. 
16. Akhter MP, Fan Z, Rho JY. Bone intrinsic material properties in three inbred mouse strains. Calcified Tissue Int. 2004;75:416-20.

17. Akhter MP, Cullen DM, Pedersen EA, Kimmel DB, Reeker RR. Bone response to in vivo mechanical loading in two breeds of mice. Calcified Tissue Int. 1998;63:442-9.

18. Li X, Gu W, Masinde G, Hamilton-Ulland M, Rundle CH, Mohan $\mathrm{S}$, et al. Genetic variation in bone-regenerative capacity among inbred strains of mice. Bone. 2001;29:134-40.

19. Manigrasso MB, O'Connor JP. Comparison of fracture healing among different inbred mouse strains. Calcified Tissue Int. 2008;82:465-74.

20. Haffner-Luntzer M, Heilmann A, Rapp AE, Beie S, Schinke T, Amling M, et al. Midkine-deficiency delays chondrogenesis during the early phase of fracture healing in mice. PLoS One. 2014;9: e116282.

21. Egermann M, Goldhahn J, Schneider E. Animal models for fracture treatment in osteoporosis. Osteoporos Int. 2005;16 Suppl 2: S129-38.

22. Ibrahim N, Mohamad S, Mohamed N, Shuid AN. Experimental fracture protocols in assessments of potential agents for osteoporotic fracture healing using rodent models. Curr Drug Targets. 2013;14:1642-50.

23. Bonnarens F, Einhorn TA. Production of a standard closed fracture in laboratory animal bone. J Orthop Res. 1984;2:97-101.

24. Histing T, Klein M, Stieger A, Stenger D, Steck R, Matthys R, et al. A new model to analyze metaphyseal bone healing in mice. J Surg Res. 2012;178:715-21.

25. Garcia P, Histing T, Holstein JH, Klein M, Laschke MW, Matthys $\mathrm{R}$, et al. Rodent animal models of delayed bone healing and nonunion formation: a comprehensive review. Eur Cell Mater. 2013;26:1-14.

26. Klein M, Stieger A, Stenger D, Scheuer C, Holstein JH, Pohlemann T, et al. Comparison of healing process in open osteotomy model and open fracture model: delayed healing of osteotomies after intramedullary screw fixation. J Orthop Res. 2015;33:971-8.

27. Holstein JH, Garcia P, Histing T, Kristen A, Scheuer C, Menger $\mathrm{MD}$, et al. Advances in the establishment of defined mouse models for the study of fracture healing and bone regeneration. $\mathrm{J}$ Orthop Trauma. 2009;23:S31-8.

28. Garcia P, Herwerth S, Matthys R, Holstein JH, Histing T, Menger $\mathrm{MD}$, et al. The LockingMouseNail - a new implant for standardized stable osteosynthesis in mice. J Surg Res. 2011;169:220-6.

29. Röntgen V, Blakytny R, Matthys R, Landauer M, Wehner T, Göckelmann M, et al. Fracture healing in mice under controlled rigid and flexible conditions using an adjustable external fixator. J Orthop Res. 2010;28:1456-62.

30. Histing T, Garcia P, Matthys R, Leidinger M, Holstein JH, Kristen A, et al. An internal locking plate to study intramembranous bone healing in a mouse femur fracture model. J Orthop Res. 2010;28: 397-402.

31. Gaston MS, Simpson AH. Inhibition of fracture healing. J Bone Joint Surg (Br). 2007;89:1553-60.

32. Bain SD, Bailey MC, Celino DL, Lantry MM, Edwards MW. High-dose estrogen inhibits bone resorption and stimulates bone formation in the ovariectomized mouse. J Bone Miner Res. 1993;8:435-42.

33. Thompson DD, Simmons HA, Pirie CM, Ke HZ. FDA guidelines and animal models for osteoporosis. Bone. 1995;17:125S-33S.

34. Beil FT, Barvencik F, Gebauer M, Seitz S, Rueger JM, Ignatius A, et al. Effects of estrogen on fracture healing in mice. J Trauma. 2010;69:1259-65.
35. Wehrle E, Liedert A, Heilmann A, Wehner T, Bindl R, Fischer L, et al. The impact of low-magnitude high-frequency vibration on fracture healing is profoundly influenced by the oestrogen status in mice. Dis Model Mech. 2015;8:93-104. Molecular characterization of osteoporotic fracture healing in aged mice and the effects of mechanostimulation.

36. Nikolaou VS, Efstathopoulos N, Kontakis G, Kanakaris NK, Giannoudis PV. The influence of osteoporosis in femoral fracture healing time. Injury. 2009;40:663-8.

37. Li W, Wang K, Liu Z, Ding W. HIF-1alpha change in serum and callus during fracture healing in ovariectomized mice. Int $\mathrm{J}$ Clin Exp Pathol. 2015;8:117-26. Molecular analysis of osteoporotic fracture healing in mice.

38. Lu C, Miclau T, Hu D, Hansen E, Tsui K, Puttlitz C, et al. Cellular basis for age-related changes in fracture repair. J Orthop Res. $2005 ; 23: 1300-7$

39. Histing T, Kuntz S, Stenger D, Scheuer C, Garcia P, Holstein JH, et al. Delayed fracture healing in aged senescence-accelerated P6 mice. J Investig Surg. 2013;26:30-5. Investigation of senile fracture healing in mice.

40. Doyon AR, Ferries IK, Li J. Glucocorticoid attenuates the anabolic effects of parathyroid hormone on fracture repair. Calcif Tissue Int. 2010;87:68-76.

41. Kasahara T, Imai S, Kojima H, Katagi M, Kimura H, Chan L, et al. Malfunction of bone marrow-derived osteoclasts and the delay of bone fracture healing in diabetic mice. Bone. 2010;47:617-25.

42. Timmen M, Hidding H, Wieskotter B, Baum W, Pap T, Raschke $\mathrm{MJ}$, et al. Influence of antiTNF-alpha antibody treatment on fracture healing under chronic inflammation. BMC Musculoskelet Disord. 2014;15:184. Influence of chronic inflammation on fracture healing in mice.

43. Lauing KL, Sundaramurthy S, Nauer RK, Callaci JJ. Exogenous activation of Wnt/beta-catenin signaling attenuates binge alcoholinduced deficient bone fracture healing. Alcohol Alcohol. 2014;49:399-408. Insights into the pathopysiology of alcoholinduced delayed fracture healing in mice.

44. El-Zawawy HB, Gill CS, Wright RW, Sandell LJ. Smoking delays chondrogenesis in a mouse model of closed tibial fracture healing. J Orthop Res. 2006;24:2150-8.

45. Tsitsilonis S, Seemann R, Misch M, Wichlas F, Haas NP, SchmidtBleek K, et al. The effect of traumatic brain injury on bone healing: an experimental study in a novel in vivo animal model. Injury. 2015;46:661-5.

46. Wichmann MW, Arnoczky SP, DeMaso CM, Ayala A, Chaudry $\mathrm{IH}$. Depressed osteoblast activity and increased osteocyte necrosis after closed bone fracture and hemorrhagic shock. J Trauma. 1996;41:628-33

47. Lichte P, Kobbe P, Pfeifer R, Campbell GC, Beckmann R, Tohidnezhad $\mathrm{M}$, et al. Impaired fracture healing after hemorrhagic shock. Mediators Inflamm. 2015;2015:132451.

48. Kemmler J, Bindl R, McCook O, Wagner F, Gröger M, Wagner K, et al. Exposure to $100 \%$ oxygen abolishes the impairment of fracture healing after thoracic trauma. PLoS One. 2015. Influence of acute inflammation induced by a severe trauma and oxygen therapy on fracture healing in mice.

49. Liu R, Birke O, Morse A, Peacock L, Mikulec K, Little DG, et al. Myogenic progenitors contribute to open but not closed fracture repair. BMC Musculoskelet Disord. 2011;12:288.

50. Kesson CM, Morris N, Mc CA. Generalized osteoporosis in old age. Ann Rheum Dis. 1947;6:146-61.

51. Silbermann M, Weiss A, Reznick AZ, Eilam Y, Szydel N, Gershon D. Age-related trend for osteopenia in femurs of female C57BL/6 mice. Compr Gerontol A. 1987;1:45-51. 
52. Weiss A, Arbell I, Steinhagen-Thiessen E, Silbermann M. Structural changes in aging bone: osteopenia in the proximal femurs of female mice. Bone. 1991;12:165-72.

53. Jilka RL, Weinstein RS, Takahashi K, Parfitt AM, Manolagas SC. Linkage of decreased bone mass with impaired osteoblastogenesis in a murine model of accelerated senescence. J Clin Invest. 1996;97:1732-40.

54. Kawaguchi H, Manabe N, Miyaura C, Chikuda H, Nakamura K, Kuro-o M. Independent impairment of osteoblast and osteoclast differentiation in klotho mouse exhibiting low-turnover osteopenia. J Clin Invest. 1999;104:229-37.

55. Kuro-o M, Matsumura Y, Aizawa H, Kawaguchi H, Suga T, Utsugi T, et al. Mutation of the mouse klotho gene leads to a syndrome resembling ageing. Nature. 1997;390:45-51.

56. Yan W, Li X. Impact of diabetes and its treatments on skeletal diseases. Front Med. 2013;7:81-90.

57. Wukich DK, Joseph A, Ryan M, Ramirez C, Irrgang JJ. Outcomes of ankle fractures in patients with uncomplicated versus complicated diabetes. Foot Ankle Int. 2011;32:120-30.

58. Fajardo RJ, Karim L, Calley VI, Bouxsein ML. A review of rodent models of type 2 diabetic skeletal fragility. J Bone Miner Res. 2014;29:1025-40. Review about diabetic mouse models.

59. Forslund JM, Archdeacon MT. The pathobiology of diabetes mellitus in bone metabolism, fracture healing, and complications. Am J Orthop (Belle Mead NJ). 2015;44:453-7.

60. Takahashi K, Setoguchi T, Tawaratsumida H, Arishima Y, Tominaga H, Ishidou Y, et al. Risk of low bone mineral density in patients with rheumatoid arthritis treated with biologics. BMC Musculoskelet Disord. 2015;16:269.

61. Mori Y, Kuwahara Y, Chiba S, Kogre A, Baba K, Kamimura M, et al. Bone mineral density of postmenopausal women with rheumatoid arthritis depends on disease duration regardless of treatment. J Bone Miner Metab. 2015.

62. Shanbhogue VV, Mitchell DM, Rosen CJ, Bouxsein ML. Type 2 diabetes and the skeleton: new insights into sweet bones. Lancet Diabetes Endocrinol. 2015:S2213-8587(15)00283-1.

63. Brown ML, Yukata K, Farnsworth CW, Chen DG, Awad H, Hilton MJ, et al. Delayed fracture healing and increased callus adiposity in a C57BL/6J murine model of obesity-associated type 2 diabetes mellitus. PLoS One. 2014;9:e99656.

64. Yee CS, Xie L, Hatsell S, Hum N, Murugesh D, Economides AN, et al. Sclerostin antibody treatment improves fracture outcomes in a Type I diabetic mouse model. Bone. 2015.

65. Chen XX, Baum W, Dwyer D, Stock M, Schwabe K, Ke HZ, et al. Sclerostin inhibition reverses systemic, periarticular and local bone loss in arthritis. Ann Rheum Dis. 2013;72:1732-6.

66. Recknagel S, Bindl R, Kurz J, Wehner T, Ehrnthaller C, Knöferl MW, et al. Experimental blunt chest trauma impairs fracture healing in rats. J Orthop Res. 2011;29:734-9.

67. Boes M, Kain M, Kakar S, Nicholls F, Cullinane D, Gerstenfeld L, et al. Osteogenic effects of traumatic brain injury on experimental fracture-healing. J Bone Joint Surg Am. 2006;88:738-43.

68. Bhandari M, Tornetta 3rd P, Sprague S, Najibi S, Petrisor B, Griffith L, et al. Predictors of reoperation following operative management of fractures of the tibial shaft. J Orthop Trauma. 2003;17:353-61.

69. Bastian O, Pillay J, Alblas J, Leenen L, Koenderman L, Blokhuis T. Systemic inflammation and fracture healing. J Leukoc Biol. 2011;89:669-73.

70. Bidner SM, Rubins IM, Desjardins JV, Zukor DJ, Goltzman D. Evidence for a humoral mechanism for enhanced osteogenesis after head injury. J Bone Joint Surg Am. 1990;72:1144-9.

71. Gebhard F, Huber-Lang M. Polytrauma - pathophysiology and management principles. Langenbeck's Arch Surg. 2008;393: 825-31.
72. Lefering R, Paffrath T, Neunaber U. Trauma register DGU annual report. German Trauma Society (DGU), Committee on Emergency Medicine, Intensive Care and Trauma Management (Section NIS), and AUC-Academy of Trauma Surgery; 2013.

73. Histing T, Stenger D, Scheuer C, Metzger W, Garcia P, Holstein $\mathrm{JH}$, et al. Pantoprazole, a proton pump inhibitor, delays fracture healing in mice. Calcif Tissue Int. 2012;90:507-14.

74. Holstein JH, Karabin-Kehl B, Scheuer C, Garcia P, Histing T, Meier C, et al. Endostatin inhibits callus remodeling during fracture healing in mice. J Orthop Res. 2013;31:1579-84.

75. Simonet WS, Lacey DL, Dunstan CR, Kelley M, Chang MS, Luthy R, et al. Osteoprotegerin: a novel secreted protein involved in the regulation of bone density. Cell. 1997;89:309-19.

76. Lacey DL, Timms E, Tan HL, Kelley MJ, Dunstan CR, Burgess T, et al. Osteoprotegerin ligand is a cytokine that regulates osteoclast differentiation and activation. Cell. 1998;93:165-76.

77. Yasuda H, Shima N, Nakagawa N, Yamaguchi K, Kinosaki M, Mochizuki S, et al. Osteoclast differentiation factor is a ligand for osteoprotegerin/osteoclastogenesis-inhibitory factor and is identical to TRANCE/RANKL. Proc Natl Acad Sci U S A. 1998;95: 3597-602.

78. Udagawa N, Takahashi N, Yasuda H, Mizuno A, Itoh K, Ueno Y, et al. Osteoprotegerin produced by osteoblasts is an important regulator in osteoclast development and function. Endocrinology. 2000;141:3478-84.

79. Kostenuik PJ, Nguyen HQ, McCabe J, Warmington KS, Kurahara C, Sun N, et al. Denosumab, a fully human monoclonal antibody to RANKL, inhibits bone resorption and increases BMD in knockin mice that express chimeric (murine/human) RANKL. J Bone Miner Res. 2009;24:182-95.

80. Gerstenfeld LC, Sacks DJ, Pelis M, Mason ZD, Graves DT, Barrero M, et al. Comparison of effects of the bisphosphonate alendronate versus the RANKL inhibitor denosumab on murine fracture healing. J Bone Miner Res. 2009;24:196-208.

81. Bekker PJ, Holloway DL, Rasmussen AS, Murphy R, Martin SW, Leese PT, et al. A single-dose placebo-controlled study of AMG 162 , a fully human monoclonal antibody to RANKL, in postmenopausal women. J Bone Miner Res. 2004;19:1059-66.

82. Bolognese MA, Teglbjaerg CS, Zanchetta JR, Lippuner K, McClung MR, Brandi ML, et al. Denosumab significantly increases DXA BMD at both trabecular and cortical sites: results from the FREEDOM study. J Clin Densitom. 2013;16:147-53.

83. McClung MR, Lewiecki EM, Cohen SB, Bolognese MA, Woodson GC, Moffett AH, et al. Denosumab in postmenopausal women with low bone mineral density. N Engl J Med. 2006;354: 821-31.

84. McClung MR, Lewiecki EM, Geller ML, Bolognese MA, Peacock M, Weinstein RL, et al. Effect of denosumab on bone mineral density and biochemical markers of bone turnover: 8 -year results of a phase 2 clinical trial. Osteoporos Int. 2013;24:227-35.

85. McClung MR, Boonen S, Torring O, Roux C, Rizzoli R, Bone $\mathrm{HG}$, et al. Effect of denosumab treatment on the risk of fractures in subgroups of women with postmenopausal osteoporosis. J Bone Miner Res. 2012;27:211-8.

86. Simon JA, Recknor C, Moffett Jr AH, Adachi JD, Franek E, Lewiecki EM, et al. Impact of denosumab on the peripheral skeleton of postmenopausal women with osteoporosis: bone density, mass, and strength of the radius, and wrist fracture. Menopause. 2013;20:130-7.

87. Van Hul W, Balemans W, Van Hul E, Dikkers FG, Obee H, Stokroos RJ, et al. Van Buchem disease (hyperostosis corticalis generalisata) maps to chromosome 17q12-q21. Am J Hum Genet. 1998;62:391-9.

88. Winkler DG, Sutherland MK, Geoghegan JC, Yu C, Hayes T, Skonier JE, et al. Osteocyte control of bone formation via sclerostin, a novel BMP antagonist. EMBO J. 2003;22:6267-76. 
89. Li X, Zhang Y, Kang H, Liu W, Liu P, Zhang J, et al. Sclerostin binds to LRP5/6 and antagonizes canonical Wnt signaling. J Biol Chem. 2005;280:19883-7.

90. Li X, Ominsky MS, Warmington KS, Morony S, Gong J, Cao J, et al. Sclerostin antibody treatment increases bone formation, bone mass, and bone strength in a rat model of postmenopausal osteoporosis. J Bone Miner Res. 2009;24:578-88.

91. Ominsky MS, Li C, Li X, Tan HL, Lee E, Barrero M, et al. Inhibition of sclerostin by monoclonal antibody enhances bone healing and improves bone density and strength of nonfractured bones. J Bone Miner Res. 2011;26:1012-21.

92. Hamann C, Rauner M, Hohna Y, Bernhardt R, Mettelsiefen J, Goettsch C, et al. Sclerostin antibody treatment improves bone mass, bone strength, and bone defect regeneration in rats with type 2 diabetes mellitus. J Bone Miner Res. 2013;28:627-38.

93. McClung MR, Grauer A, Boonen S, Bolognese MA, Brown JP, Diez-Perez A, et al. Romosozumab in postmenopausal women with low bone mineral density. N Engl J Med. 2014;370:41220. Promising clinical study about the effects of antisclerostin therapy in osteoporotic women.

94. Duong LT. Therapeutic inhibition of cathepsin K-reducing bone resorption while maintaining bone formation. Bonekey Rep. 2012;1:67.

95. Choi HJ. New antiresorptive therapies for postmenopausal osteoporosis. J Menopausal Med. 2015;21:1-11.

96. Saftig P, Hunziker E, Wehmeyer O, Jones S, Boyde A, Rommerskirch W, et al. Impaired osteoclastic bone resorption leads to osteopetrosis in cathepsin-K-deficient mice. Proc Natl Acad Sci U S A. 1998;95:13453-8.

97. Li CY, Jepsen KJ, Majeska RJ, Zhang J, Ni R, Gelb BD, et al. Mice lacking cathepsin $\mathrm{K}$ maintain bone remodeling but develop bone fragility despite high bone mass. J Bone Miner Res. 2006;21: 865-75.

98. Kiviranta R, Morko J, Uusitalo H, Aro HT, Vuorio E, Rantakokko $\mathrm{J}$. Accelerated turnover of metaphyseal trabecular bone in mice overexpressing cathepsin K. J Bone Miner Res. 2001;16:1444-52.

99. Bone HG, Dempster DW, Eisman JA, Greenspan SL, McClung MR, Nakamura T, et al. Odanacatib for the treatment of postmenopausal osteoporosis: development history and design and participant characteristics of LOFT, the Long-Term Odanacatib Fracture Trial. Osteoporos Int. 2015;26:699-712.

100. Zhang C, Evans T. BMP-like signals are required after the midblastula transition for blood cell development. Dev Genet. 1996;18:267-78.

101. Mishina Y, Suzuki A, Ueno N, Behringer RR. Bmpr encodes a type I bone morphogenetic protein receptor that is essential for gastrulation during mouse embryogenesis. Genes Dev. 1995;9: 3027-37.

102. Tsuji K, Bandyopadhyay A, Harfe BD, Cox K, Kakar S, Gerstenfeld L, et al. BMP2 activity, although dispensable for bone formation, is required for the initiation of fracture healing. Nat Genet. 2006;38:1424-9.

103. Welch RD, Jones AL, Bucholz RW, Reinert CM, Tjia JS, Pierce WA, et al. Effect of recombinant human bone morphogenetic protein-2 on fracture healing in a goat tibial fracture model. J Bone Miner Res. 1998;13:1483-90.
104. Murnaghan M, McIlmurray L, Mushipe MT, Li G. Time for treating bone fracture using rhBMP-2: a randomised placebo controlled mouse fracture trial. J Orthop Res. 2005;23:625-31.

105. Ablove RH, Abrams SS. The use of BMP-2 and screw exchange in the treatment of scaphoid fracture non-union. Hand Surg. 2015;20:167-71.

106. Nordsletten L. Recent developments in the use of bone morphogenetic protein in orthopaedic trauma surgery. Curr Med Res Opin. 2006;22(1):S13-7-S23.

107. Yao X, Huang J, Zhong H, Shen N, Faggioni R, Fung M, et al. Targeting interleukin-6 in inflammatory autoimmune diseases and cancers. Pharmacol Ther. 141:125-39.

108. Smolen JS, Beaulieu A, Rubbert-Roth A, Ramos-Remus C, Rovensky J, Alecock E, et al. Effect of interleukin-6 receptor inhibition with tocilizumab in patients with rheumatoid arthritis (OPTION study): a double-blind, placebo-controlled, randomised trial. Lancet. 2008;371:987-97.

109. Mestas J, Hughes CC. Of mice and not men: differences between mouse and human immunology. J Immunol. 2004;172:2731-8.

110. Seok J, Warren HS, Cuenca AG, Mindrinos MN, Baker HV, Xu $\mathrm{W}$, et al. Genomic responses in mouse models poorly mimic human inflammatory diseases. Proc Natl Acad Sci U S A. 2013;110: $3507-12$. Highly publicized research report about the inflammatory response in mice and humans.

111.• Osuchowski MF, Remick DG, Lederer JA, Lang CH, Aasen AO, Aibiki M, et al. Abandon the mouse research ship? Not just yet! Shock. 2014;41:463-75. Critical evaluation of the above mentioned study.

112. Cauwels A, Vandendriessche B, Brouckaert P. Of mice, men, and inflammation. Proc Natl Acad Sci U S A. 2013;110:E3150.

113. Takao K, Miyakawa T. Genomic responses in mouse models greatly mimic human inflammatory diseases. Proc Natl Acad Sci U S A. 2015;112:1167-72.

114. Shultz LD, Ishikawa F, Greiner DL. Humanized mice in translational biomedical research. Nat Rev Immunol. 2007;7:118-30.

115. Safinia N, Becker PD, Vaikunthanathan T, Xiao F, Lechler R, Lombardi G. Humanized mice as preclinical models in transplantation. Methods Mol Biol. 2016;1371:177-96.

116. Holzapfel BM, Wagner F, Thibaudeau L, Levesque JP, Hutmacher DW. Concise review: humanized models of tumor immunology in the 21st century: convergence of cancer research and tissue engineering. Stem Cells. 2015;33:1696-704.

117. Holzapfel BM, Wagner F, Loessner D, Holzapfel NP, Thibaudeau L, Crawford R, et al. Species-specific homing mechanisms of human prostate cancer metastasis in tissue engineered bone. Biomaterials. 2014;35:4108-15.

118. Hesami P, Holzapfel BM, Taubenberger A, Roudier M, Fazli L, Sieh $\mathrm{S}$, et al. A humanized tissue-engineered in vivo model to dissect interactions between human prostate cancer cells and human bone. Clin Exp Metastasis. 2014.

119. Holzapfel BM, Hutmacher DW, Nowlan B, Barbier V, Thibaudeau $\mathrm{L}$, Theodoropoulos $\mathrm{C}$, et al. Tissue engineered humanized bone supports human hematopoiesis in vivo. Biomaterials. 2015;61: 103-14. 